\title{
Numerical Analysis and Experimental Verification of Eigenfrequencies of Overhead ACSR Conductor
}

\author{
Justín Murín ${ }^{1)}$, Juraj Hrabovský ${ }^{1)}$, Roman Gogola ${ }^{1)}$, Vladimír Goga ${ }^{1)}$ and František Janíček ${ }^{2)}$ \\ ${ }^{1)}$ Slovak University of Technology in Bratislava, Faculty of Electrical Engineering and Information Technology, \\ Department of Applied Mechanics and Mechatronics, Bratislava, Slovakia, e-mail: justin.murin@stuba.sk \\ ${ }^{2)}$ Slovak University of Technology in Bratislava, Faculty of Electrical Engineering and Information Technology, \\ Department of Electrical Power Engineering, Bratislava, Slovakia, e-mail: frantisek.janicek@stuba.sk
}

\begin{abstract}
This contribution deals with the modal analysis of ACSR conductor using the finite element method (FEM) and experimental measurements of eigenfrequencies. In numerical experiments for the modelling of the conductor the material properties of the chosen conductor crosssection are homogenized by the Representative Volume Element (RVE) method. The spatial modal analysis of the power line is carried out by means of our new 3D FGM beam finite element and by standard beam finite element of the commercial software ANSYS. Experimental measurements are also carried out for verification of the numerical calculation accuracy.
\end{abstract}

Keywords - ACSR conductor, finite element method, modal analysis, experimental measurements

\section{INTRODUCTION}

Vibration of overhead power lines is a very dangerous problem because it can cause collapse of overhead power lines or collapse of the whole transmission system. The overhead power lines are exposed to dynamic loads (air flow, ice-shedding, etc.) in addition to the static ones. From the mechanical point of view the conductor is a 3D system, so it can vibrate in longitudinal, horizontal and vertical directions. The torsional vibrations are possible as well. For calculation of eigenfrequencies and eigenmodes the numerical methods are the most effective, over all the finite element method. For the modal analysis the beam finite element is preferable.

The material of the conductor is inhomogeneous, therefore simplified models obtained by homogenization of material properties are used $[1,2,3]$. The heterogeneous cross-sections of several ACSR conductors are shown in Fig.1.
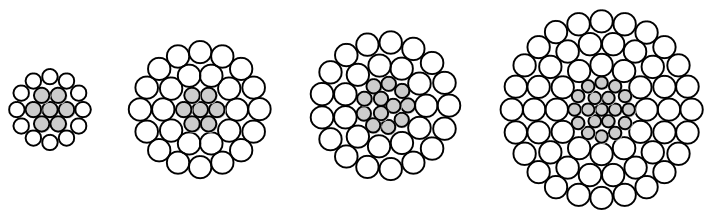

Fig. 1. Construction of ACSR conductor.

Results of the modal analysis are obtained using the commercial finite element software ANSYS and by a new 3D finite element [4]. An experimental measurement was done to verify and to compare the effectiveness and accuracy of each numerical calculation.

\section{HOMOGENIZATION OF MATERIAL PROPERTIES}

One important goal of mechanics of heterogeneous materials is to derive their effective properties from the knowledge of the constitutive laws and complex microstructural behaviour of their components.

The methods based on the homogenization theory (e.g. the mixture rules [5]) have been designed and successfully applied to determine the effective material properties of heterogeneous materials from the corresponding material behaviour of the constituents (and of the interfaces between them) and from the geometrical arrangement of the phases. In this context, the microstructure of the material under consideration is basically taken into account by the Representative Volume Element (RVE).

The homogenization techniques derived at our department (Department of Applied Mechanics and Mechatronics) for modelling the Functionally Graded Material (FGM) [1, 2] can also be used for homogenization of the ACSR conductors. In case of the conductor, the material properties vary layer-wise in the radial direction (the longitudinal variation is not assumed).

The effective homogenized material properties (electric conductance, thermal conductance, thermal expansion, stiffness) are calculated from condition, that the relevant material property of the cross-section with real construction (Fig. 2) is equal to the material property of the homogenized cross-section.

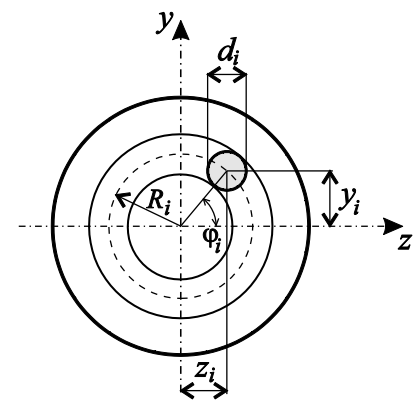

Fig. 2. Conductor cross-section.

The real cross-section parameters of the ACSR conductors are: $R_{i}$ is pitch circle of the $k^{\text {th }}$ layer, $d_{i}$ is wire diameter, $\varphi_{i}$ is the angle of circumferential position of the wire, $z_{i}$ and $y_{i}$ are the distances of the wire from the centre of the conductor cross-section. These distances of each wire can be calculated as follows: 


$$
\begin{aligned}
& y_{i}=R_{i} \sin \varphi_{i} \\
& z_{i}=R_{i} \cos \varphi_{i}
\end{aligned}
$$

Then the quadratic moment of the $i^{\text {th }}$ wire cross-sectional area $A_{i}=\pi d_{i}^{2} / 4$ according the axis $y$ and according the axis $z$ can be calculated by equations [1]:

$$
I_{y i}=\frac{\pi d_{i}^{4}}{64}+z_{i}^{2} \frac{\pi d_{i}^{2}}{4} \quad I_{z i}=\frac{\pi d_{i}^{4}}{64}+y_{i}^{2} \frac{\pi d_{i}^{2}}{4}
$$

The polar moment of the wire cross-sectional area to origin of the coordinate system $x, y$ is:

$$
I_{p i}=I_{y i}+I_{z i}
$$

Since the Young's modulus multiplied by the crosssectional area defines the axial stiffness and multiplied by the quadratic moment of the cross-section area defines the bending stiffness, we have to distinguish homogenized effective Young's modulus for axial loading $E_{L}^{N H}$ and homogenized effective Young's modulus for bending $E_{L}^{M_{y} H}$ and $E_{L}^{M_{z} H}$.

We assume that the maximum and minimum elasticity moduli for lateral and transversal bending can be calculated by equations:

$$
\begin{gathered}
E_{L \text { max }}^{M_{y} H}=\frac{\sum_{i=1}^{n} E_{i} I_{y i}}{\sum_{i=1}^{n} I_{y i}}, \quad E_{L \max }^{M_{z} H}=\frac{\sum_{i=1}^{n} E_{i} I_{z i}}{\sum_{i=1}^{n} I_{z i}} \\
E_{L \text { min }}^{M_{y} H}=\frac{\frac{\pi}{64}\left[n_{F e} d_{F e}^{4} E_{F e}+n_{A l} d_{A l}^{4} E_{A l}\right]}{\sum_{i=1}^{n} I_{y i}} \\
E_{L \text { min }}^{M_{z} H}=\frac{\frac{\pi}{64}\left[n_{F e} d_{F e}^{4} E_{F e}+n_{A l} d_{A l}^{4} E_{A l}\right]}{\sum_{i=1}^{n} I_{z i}}
\end{gathered}
$$

where $n_{F e}$ is the number of steel wires and $n_{A l}$ is the number of aluminium wires. The maximum elasticity modulus represents the case, when all wires are fixed together (e.g. after several years of lifetime), and the minimum elasticity modulus represents the case, when wires can slide over each other. In practice the effective elasticity modulus for lateral and transversal bending is assumed as average value of the maximum and minimum elasticity moduli [4]:

$$
\begin{aligned}
& E_{L}^{M_{y} H}=\frac{E_{L \max }^{M_{y} H}+E_{L \min }^{M_{y} H}}{2} \\
& E_{L}^{M_{z} H}=\frac{E_{L \max }^{M_{z} H}+E_{L \min }^{M_{z} H}}{2}
\end{aligned}
$$

The effective elasticity modulus for axial loading is:

$$
E_{L}^{N H}=\frac{\sum_{i=1}^{n} E_{i} A_{i}}{\sum_{i=1}^{n} A_{i}}
$$

Here, $E_{i}$ is the elasticity modulus of the $i^{\text {th }}$ wire, and $n$ is number of the wires.

The effective elasticity modulus for lateral and transversal shears

$$
G_{L z}^{H}=\frac{\sum_{i=1}^{n} k_{z, i}^{s m} G_{i} A_{i}}{k_{z}^{s m} A}, \quad G_{L z}^{H}=\frac{\sum_{k=1}^{n} k_{z, i}^{s m} G_{i} A_{i}}{k_{z}^{s m} A}
$$

Where $G_{i}=E_{i} / 2\left(1+v_{i}\right)$ is the shear modulus of the $i^{\text {th }}$ wire, $A=\sum_{i=1}^{n} A_{i}$ is the cross-sectional area of the whole real cross-section and $v_{i}$ is its Poisson's ratio. Again, $k_{y, i}^{s m}$ and $k_{y}^{s m}$ are the shear correction factors for the $i^{\text {th }}$ wire and the whole cross-section, respectively. These constants have to be calculated by a special method [4]. The effective elasticity modulus for torsion is:

$$
G_{L}^{M_{x} H}(x)=\frac{\sum_{i=1}^{n} G_{i} I_{p i}}{\sum_{i=1}^{n} I_{p i}}
$$

The effective mass density for axial beam vibration is:

$$
\rho_{L}^{N H}=\frac{\sum_{i=1}^{n} \rho_{i} A_{i}}{\sum_{i=1}^{n} A_{i}}
$$

and the effective mass density for torsional vibration is:

$$
\rho_{L}^{M_{x} H}=\frac{\sum_{i=1}^{n} \rho_{i} I_{p i}}{\sum_{i=1}^{n} I_{p i}}
$$

where, $\rho_{i}$ is the mass density of the $i^{\text {th }}$ wire.

\section{3D FGM BEAM FINITE ELEMENT EQUATIONS}

Let us consider a 3D straight finite beam element (Timoshenko beam theory and Saint-Venant torsion theory) of a doubly symmetric cross-section. The nodal degrees of freedom at the node $i$ are: the displacements $u_{i}$, $v_{i}, w_{i}$ in the local axis direction $x, y, z$, and the crosssectional area rotations $-\varphi_{x, i}, \varphi_{y, i}, \varphi_{z, i}$. The degrees of freedom at the node $j$ are denoted in a similar manner. The internal forces at the node $i$ are: axial force $N_{i}$, transversal forces $R_{y, i}$ and $R_{z, i}$, bending moments $M_{y, i}$ and $M_{z, i}$, and 
torsion moment $M_{x, i}$. Establishing of the local 3D FGM

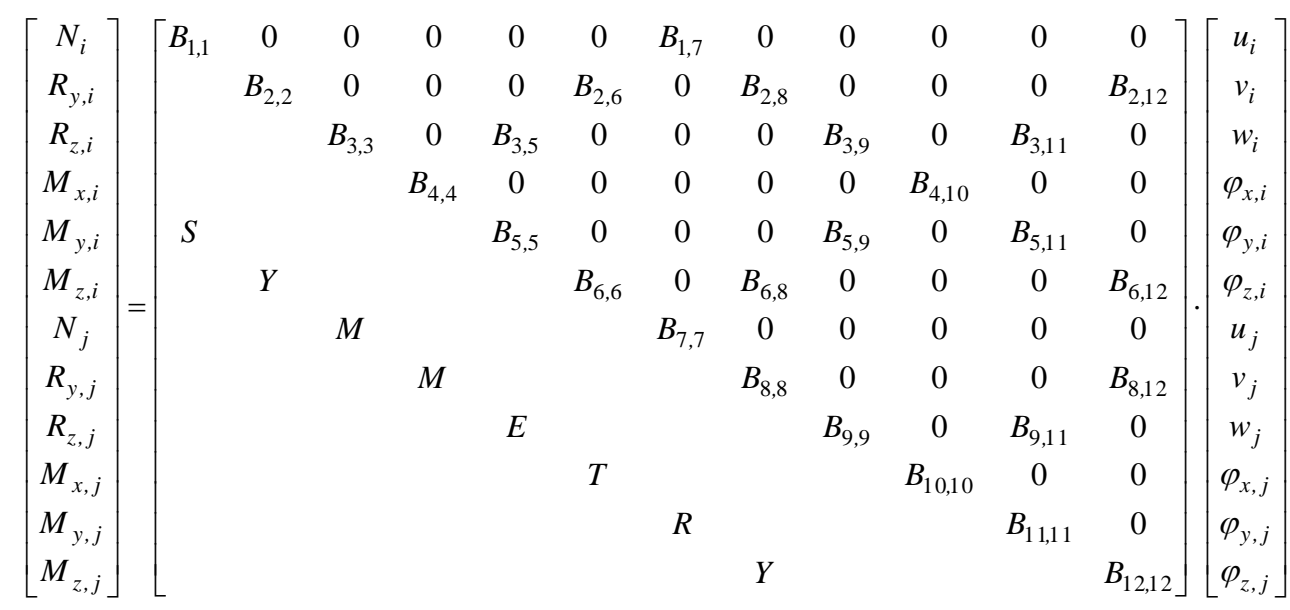

In (13), the terms $B_{i, j}$ contain the linear and linearized geometric non-linear stiffness terms - containing the axial force effect on the flexural beam stiffness matrix $K$ and consistent mass matrix $M$ [4]:

$$
B=K-\omega^{2} M
$$

where $\omega$ is the natural frequency. The shear correction is accounted as well. The global stiffness matrix of the beam structures can be established by classical methods. Establishing of the local and global stiffness matrices as well as the whole solution procedure were coded by the software MATHEMATICA [12].

\section{NUMERICAL SIMULATIONS AND EXPERIMENTAL MEASUREMENTS}

For the numerical simulations and experimental measurements the single power line with the span length $L=19.9 \mathrm{~m}$ and the height difference between the points of attachment $y_{h}=0.8 \mathrm{~m}$ has been considered (Fig. 3). In this case the maximum deflection of the power line $[6,7]$ is minimal and therefore was not calculated, because the span is small. The constant tensile force in the conductor for each numerical calculations and experimental measurements were: $F_{H 1}=1.65 \mathrm{kN}, F_{H 2}=4.75 \mathrm{kN}$ and $F_{H 3}=6.68 \mathrm{kN}$.

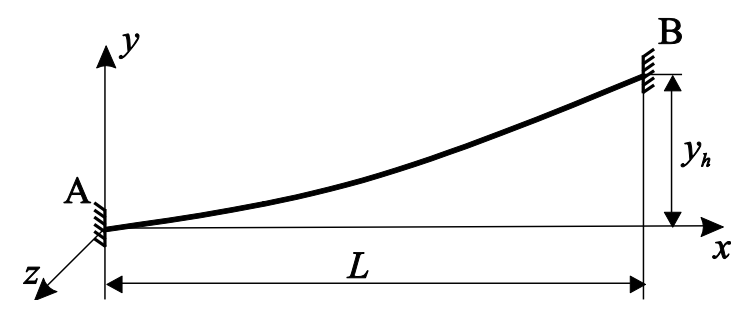

Fig. 3. Model of overhead power line for modal analysis.

A symmetric conductor marked as AlFe 42/7 which is constructed from 1 steel wire in the centre of the conductor and 6 aluminium wires (see Fig. 4) has been used. The diameter of the steel wire is $d_{F e}=3 \mathrm{~mm}$ and the diameter of the aluminium wires is $d_{A l}=3 \mathrm{~mm}$. The rated tensile strength (RTS) of the chosen conductor is $F_{R T S}=15.27 \mathrm{kN}[8]$.

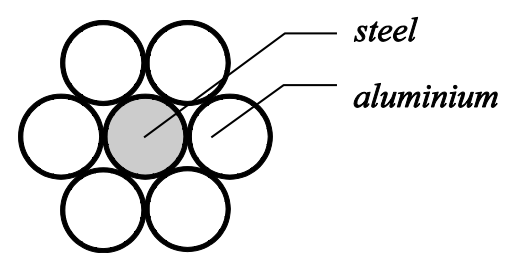

Fig. 4. Cross-section of the used ACSR conductor.

Material properties of the material from which the conductor is made are $[9,10]$ :

- Steel:

- elasticity modulus $E_{F e}=207000 \mathrm{MPa}$,

- Poisson's ratio $v_{F e}=0.28$,

- $\quad$ mass density $\rho_{F e}=7780 \mathrm{~kg} \cdot \mathrm{m}^{-3}$;

\section{- Aluminium:}

- elasticity modulus $E_{A l}=69000 \mathrm{MPa}$,

- Poisson's ratio $v_{A l}=0.33$,

- $\quad$ mass density $\rho_{A l}=2703 \mathrm{~kg} \cdot \mathrm{m}^{-3}$.

For numerical simulations a simplified model was used. For simplifying the model of the ACSR conductor the homogenized material properties are calculated $[1,2,3]$.

The effective cross-sections of the conductor parts are: $A_{F e}=7.07 \mathrm{~mm}^{2}, A_{A l}=42.41 \mathrm{~mm}^{2}$ and the effective crosssectional area of the whole conductor is $A=49.48 \mathrm{~mm}^{2}$. The effective quadratic moments of the conductor crosssectional area are: $I_{z}=I_{y}=218.68 \mathrm{~mm}^{4}$. The effective circular cross-section of the conductor is constant with diameter $d_{e f}=7.94 \mathrm{~mm}$. The effective material properties of the used conductor are:

$$
\begin{aligned}
& E_{L}^{N H}=88714.29 \mathrm{MPa} \\
& E_{L}^{M_{y} H}=E_{L}^{M_{z} H}=40704.43 \mathrm{MPa} \\
& G_{L_{y}}^{H}=G_{L_{z}}^{H}=34120.91 \mathrm{MPa} \\
& G_{L}^{M_{x} H}(x)=27503.49 \mathrm{MPa} \\
& \rho_{L}^{N H}=3460.49 \mathrm{kgm}^{-3} \\
& \rho_{L}^{M_{x}{ }^{H}}=2795.31 \mathrm{~kg} \cdot \mathrm{m}^{-3} \\
& v_{L}^{N H}=0.323
\end{aligned}
$$


where $E_{L}^{N H}$ is the elastic modulus for tension, $E_{L}^{M_{y} H}, E_{L}^{M_{z} H}$ are the elastic moduli for bending around axis $y$ and $z$, respectively. $G_{L_{y}}^{H}, G_{L_{z}}^{H}$ are the effective shear moduli, $G_{L}^{M_{x} H}(x)$ is the effective elasticity modulus for torsion, $\rho_{L}^{N H}$ is the effective mass density for axial beam vibration, $\rho_{L}^{M_{x} H}$ is the effective mass density for torsional vibration and $v_{L}^{N H}$ is the effective Poisson's ratio. These calculated effective material properties have been used in the modal analyses of the single power lines. The first three flexural eigenfrequencies $f[\mathrm{~Hz}]$ in the plane $x y$ (vertical) and the first three flexural eigenfrequencies $f$ [Hz] in the plane $x z$ (horizontal) have been found with a mesh 200 of BEAM188 elements of the FEM program ANSYS [11]. The same problem has been solved using the new 3D beam finite element (3D NFE) for the modal analysis of composite beam structures [4] with a mesh 80 of $3 \mathrm{D}$ FGM elements (the calculation is performed using the software MATHEMATICA).

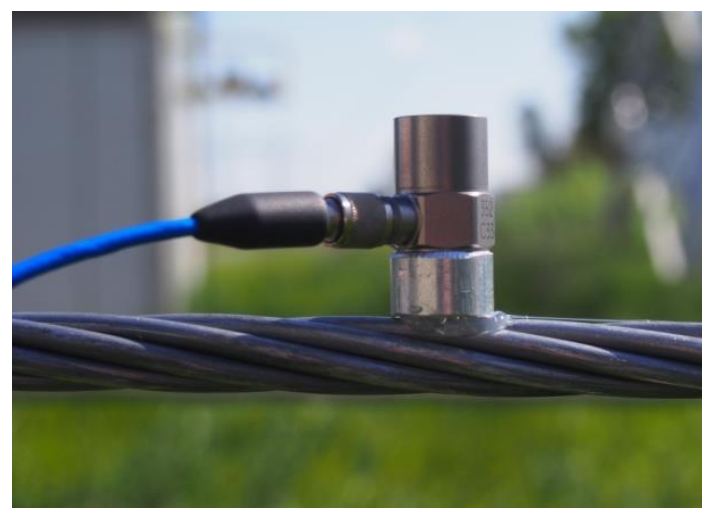

Fig. 5. Piezoelectric accelerometer attached on the conductor.
Two bolted strain clamps were used for fixing the conductor on two ends of the span; two IEPE piezoelectric accelerometers with the range of $\pm 50 \mathrm{~g}$ (Fig. 5) were used for experimental modal analyses to determine the flexural eigenfrequencies. For scanning the signals from the accelerometers 2 way oscilloscope with USB connection to the $\mathrm{PC}$ was used. The range of the oscilloscope is $20 \mathrm{MHz}$. The tension in the conductor is measured with one load cell with sensing range $F_{\max }=10 \mathrm{kN}$ (Fig 6), which is close to the conductor attachment point.

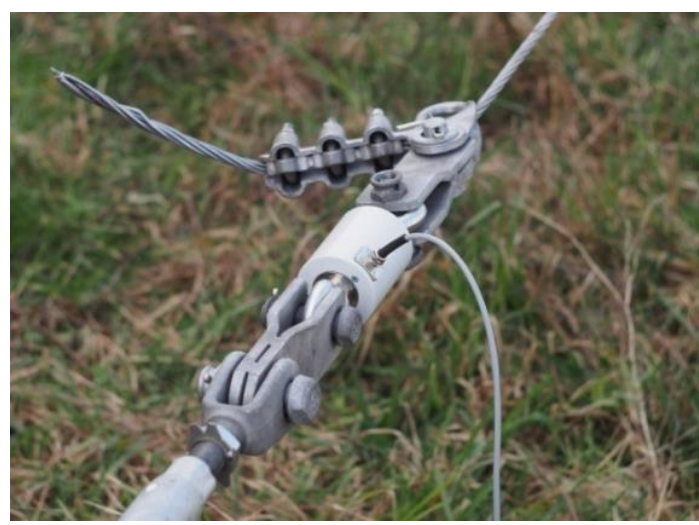

Fig. 6. Attaching of the load cell to sensing the axial force in conductor.

The data from the accelerometers placed on the conductor is shown in Fig. 7.

To obtain the frequency spectrum (Fig. 8) the Fast Fourier Transformation (FFT) of the measured data was realized by software LabView [13]. The flexural mode shapes were evaluated using software ANSYS. The results of numerical analyses and experimental measurements are presented in Tab. 1-3. First three flexural eigenfrequencies in horizontal and three flexural eigenfrequencies in vertical plane were investigated.

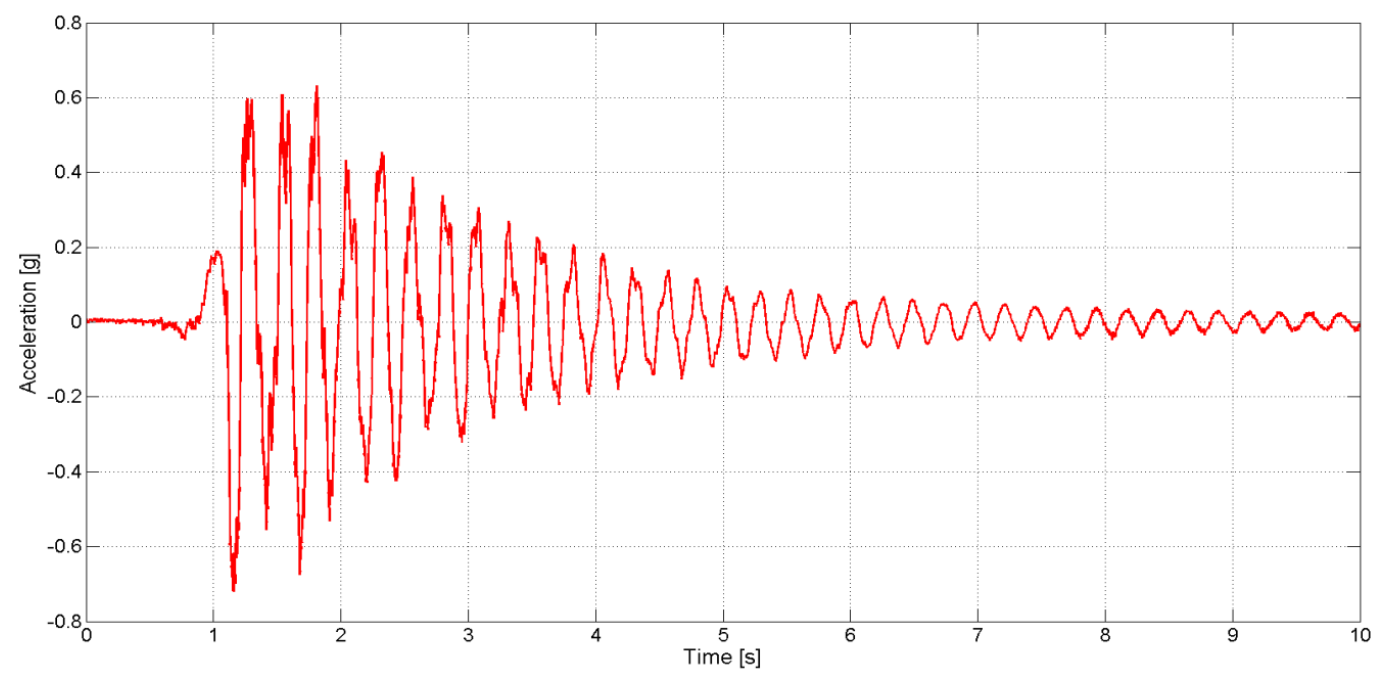

Fig. 7. Measured data of acceleration of the overhead ACSR conductor. 


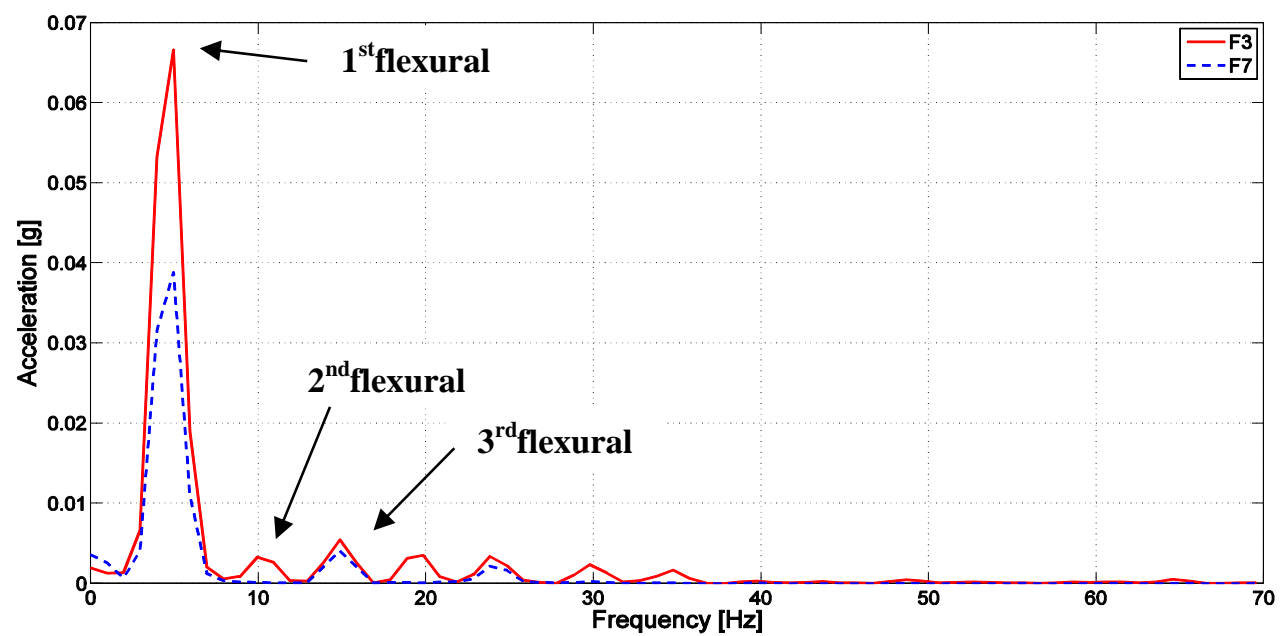

Fig. 8. Measured flexural eigenfrequencies of the used ACSR conductor for the tension $F_{H}=6.68 \mathrm{kN}$ at times $t=3 \mathrm{~s}$ and $t=7 \mathrm{~s}$.

TABLE I

First Three Horizontal and Vertical Measured and Numerically Calculated Eigenfrequencies of the Used ACSR Power Line AT THE TENSION $F_{H}=1,65 \mathrm{KN}$

\begin{tabular}{|c|c|c|c|c|c|c|}
\hline \multicolumn{2}{|c|}{$f[\mathrm{~Hz}]$} & $f_{\text {meas }}[\mathrm{Hz}]$ & $f_{\text {ans }}[\mathrm{Hz}]$ & $f_{3 \mathbf{D}}[\mathrm{Hz}]$ & $\Delta_{\mathbf{A N S}}[\%]$ & $\Delta_{\mathbf{3 D}}[\%]$ \\
\hline \multirow{2}{*}{$1^{\text {st }}$} & horizontal & 2,23 & 2,49 & 2,47 & 11,66 & 10,74 \\
\cline { 2 - 7 } & vertical & 2,38 & 2,54 & 2,58 & 6,72 & 8,34 \\
\hline \multirow{3}{*}{$2^{\text {nd }}$} & horizontal & 4,85 & 4,98 & 4,94 & 2,68 & 1,85 \\
\cline { 2 - 7 } & vertical & 4,91 & 4,98 & 4,94 & 1,43 & 0,61 \\
\hline \multirow{3}{*}{$3^{\text {rd }}$} & horizontal & 7,23 & 7,47 & 7,41 & 3,32 & 2,51 \\
\cline { 2 - 7 } & vertical & 7,24 & 7,47 & 7,42 & 3,18 & 2,44 \\
\hline
\end{tabular}

TABLE II.

First Three Horizontal and Vertical Measured and Numerically Calculated Eigenfrequencies of the Used ACSR Power Line AT THE TENSION $F_{H}=4,75 \mathrm{KN}$

\begin{tabular}{|c|c|c|c|c|c|c|}
\hline \multicolumn{2}{|c|}{$f[\mathbf{H z}]$} & $f_{\text {meas }}[\mathrm{Hz}]$ & $f_{\text {ans }}[\mathrm{Hz}]$ & $f_{3 D}[\mathrm{~Hz}]$ & $\Delta_{\text {ANS }}[\%]$ & $\Delta_{\text {3D }}[\%]$ \\
\hline \multirow{2}{*}{$1^{\text {st }}$} & horizontal & 3,88 & 4,31 & 4,20 & 11,08 & 8,34 \\
\cline { 2 - 7 } & vertical & 3,97 & 4,32 & 4,21 & 8,82 & 6,08 \\
\hline \multirow{2}{*}{$2^{\text {nd }}$} & horizontal & 8,58 & 8,63 & 8,41 & 0,58 & $-2,01$ \\
\cline { 2 - 7 } & vertical & 8,73 & 8,63 & 8,41 & $-1,15$ & $-3,69$ \\
\hline \multirow{2}{*}{$3^{\text {rd }}$} & horizontal & 12,48 & 12,95 & 12,61 & 3,77 & 1,05 \\
\cline { 2 - 7 } & vertical & 12,64 & 12,95 & 12,61 & 2,45 & $-0,21$ \\
\hline
\end{tabular}

TABLE III.

First Three Horizontal and Vertical Measured AND Numerically CALCulated Eigenfrequencies of the Used ACSR Power Line AT THE TENSION $F_{H}=6,68 \mathrm{KN}$

\begin{tabular}{|c|c|c|c|c|c|c|}
\hline \multicolumn{2}{|c|}{$f[\mathbf{H z}]$} & $f_{\text {meas }}[\mathrm{Hz}]$ & $f_{\text {ans }}[\mathrm{Hz}]$ & $f_{3 D}[\mathrm{~Hz}]$ & $\Delta_{\mathbf{A N S}}[\%]$ & $\Delta_{\text {3D }}[\%]$ \\
\hline \multirow{2}{*}{$1^{\text {st }}$} & horizontal & 4,51 & 5,13 & 4,98 & 13,75 & 10,46 \\
\cline { 2 - 7 } & vertical & 4,72 & 5,13 & 4,99 & 8,69 & 5,62 \\
\hline \multirow{2}{*}{$2^{\text {nd }}$} & horizontal & 9,98 & 10,25 & 9,96 & 2,71 & $-0,16$ \\
\cline { 2 - 7 } & vertical & 10,23 & 10,25 & 9,96 & 0,20 & $-2,60$ \\
\hline \multirow{2}{*}{$3^{\text {rd }}$} & horizontal & 14,67 & 15,35 & 14,95 & 4,64 & 1,89 \\
\cline { 2 - 7 } & vertical & 14,97 & 15,38 & 14,95 & 2,74 & $-0,15$ \\
\hline
\end{tabular}




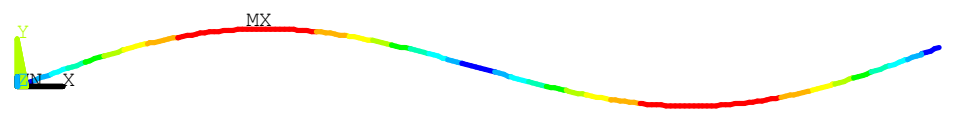

a) $2^{\text {nd }}$ eigenmode in vertical plane

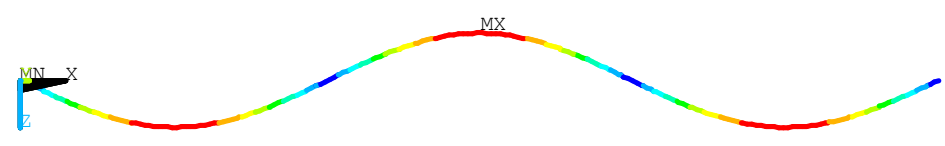

b) $3^{\text {rd }}$ eigenmode in horizontal plane

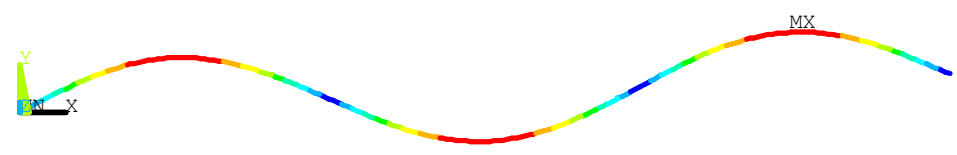

c) $3^{\text {rd }}$ eigenmode in vertical plane

Fig. 8. Eigenmodes of the used ACSR conductor for the tension $F_{H}=6.68 \mathrm{kN}$.

\section{CONCLUSION}

In the presented contribution the numerical simulation and experimental measurements of the selected ACSR conductor is presented. The numerical simulations were done by the commercial software ANSYS and by our new 3D FGM beam finite element which was implemented in the software MATHEMATICA.

From the results shown in Tab. 1-3 it is obvious that the differences between the numerical simulations and experimental measurements are very small. These results confirm the correctness of our procedure for homogenising the material properties of the ACSR conductor as well as the efficiency and accuracy of a new beam finite element for analysis of the composite structures.

\section{ACKNOWLEDGMENT}

This work was supported by the Slovak Research and Development Agency under the contract No. APVV-150326. This work was also supported by the Slovak Research and Development Agency under the contract No. APVV-0246-12 and APVV-14-0613, by Grant Agency VEGA, grant No. 1/0228/14 and 1/0453/15.

Authors are also grateful to the companies SAG Elektrovod a.s. Bratislava, Elba a.s. Kremnica and Laná a.s. Žiar nad Hronom for sponsorship materials needed for measurements.

\section{REFERENCES}

[1] J. Murin, V. Kutis, Improved mixture rules for the composite (FGM's) sandwich beam finite element, Barcelona, Spain, 2007, pp. 647-650.

[2] V. Kutiš, J. Murín, R. Belák and J. Paulech, „Beam element with spatial variation of material properties for multiphysics analysis of functionally graded materials, “ Computers and Structures, 89, pp. 1192 - 1205. Doi: 10.1016/j.compstruc.2010.10.012

[3] J. Hrabovský, Multiscale modelling and simulation of free vibration of FGM beams, Dizertačná práca, Bratislava, 2013.

[4] J. Murín, M. Aminbaghai, J. Hrabovský, V. Kutiš, J. Paulech, S. Kugler, „A new 3D FGM beam finite element for modal analysis," rev. Proceedings of the 11th WCCM, Barcelona, Spain, 2014.

[5] H. Altenbach, Mechanics of composite structural elements, Berlin: Springer-Verlag, 2003.

[6] Š. Fecko, et. al., Elektrické siete: Vonkajšie silové vedenia, Bratislava: STU v Bratislave, 1990.

[7] Š. Fecko, D. Reváková, L. Varga, J. Lago, S. Ilenin, Vonkajšie elektrické vedenia, Bratislava: Renesans, s.r.o., 2010.

[8] STN EN 50182, Vodiče na vonkajšie vedenia. Vodiče koncentricky zlanovaných kruhových drôtov, 2001.

[9] STN EN 50189, Vodiče na vonkajšie vedenia. Pozinkované ocelové drôty, 2001.

[10]STN EN 60889, Tvrdo t'ahané hlinikové drôty pre vodiče nadzemných elektrických vedení, 2001.

[11]ANSYS Swanson Analysis System, Inc., 201 Johnson Road, Houston, PA 15342/1300, USA.

[12] National Instruments Corporation, LabView, 11500 Mopac Expwy, Austin, 78759-3504 Texas.

[13]S. Wolfram Mathematica 5, Wolfram research, Inc., 2003. 